United Nations Educational Scientific and Cultural Organization and

International Atomic Energy Agency

THE ABDUS SALAM INTERNATIONAL CENTRE FOR THEORETICAL PHYSICS

\title{
A VIEW TO THE INTERMEDIATE-DEPTH VRANCEA EARTHQUAKE OF MAY 30, 1990: CASE STUDY IN NE BULGARIA
}

\author{
M. Kouteva \\ Central Laboratory for Seismic Mechanics and Earthquake Engineering, \\ Bulgarian Academy of Science, Sofia, Bulgaria, \\ G.F. Panza \\ Department of Earth Sciences, University of Trieste, Trieste, Italy \\ and \\ The Abdus Salam International Centre for Theoretical Physics, SAND Group, \\ Trieste, Italy, \\ I. Paskaleva \\ Central Laboratory for Seismic Mechanics and Earthquake Engineering, \\ Bulgarian Academy of Science, Sofia, Bulgaria \\ and \\ F. Romanelli \\ Department of Earth Sciences, University of Trieste, Trieste, Italy.
}

MIRAMARE - TRIESTE

February 2004 


\begin{abstract}
A deterministic analytical procedure for ground motion modelling, combining both modal summation and mode coupling techniques has been implemented to obtain synthetic seismic signals at Russe, NE Bulgaria, due to one of the strongest Vrancea intermediate-depth earthquakes, which occurred during the last century, May 30, 1990. The frequency content of the synthetic signals in different frequency ranges, up to 1 and $2 \mathrm{~Hz}$, has been studied separately. The results of this study, i.e. time histories and related ground motions parameters, can be used for different earthquake engineering analyses, e.g. structural performance assessments.
\end{abstract}




\section{Introduction}

During the last century, five strong Vrancea intermediate-depth earthquakes $(M>6.0)$ were significantly felt in Bulgaria. These earthquakes have been typical examples of far-reaching seismic effects, e.g. the quake of March 4, $1977(\mathrm{Mw}=7.5)$ was felt at epicentral distances up to $1000 \mathrm{~km}$ in Central Europe, and macroseismic intensities I > VIII (MSK-64) in Romania, I = VII - VIII at Russe, Bulgaria, I = V at Zagreb, Croatia and I = IV at Budapest (Hungary), were reported [Balan et al., 1982; Brankov et al., VV AA,1983]. The Vrancea seismic record and the recent deterministic seismic hazard estimates [Panza \& Vaccari, 2000 a] show that the seismic hazard in Romania and NE Bulgaria is mainly controlled by the large Vrancea intermediate-depth earthquakes. Due to these earthquakes, macroseismic intensity I = IV - VIII (MSK-64, epicentral distances 210-250km) has been reported at Russe, one of the main Bulgarian cities, fig. 1. Due to the last strong earthquake of May 30, $1990\left(\mathrm{M}_{\mathrm{w}}\right.$ $=6.9$ ) maximum ground acceleration of $114.62 \mathrm{~cm} / \mathrm{s}^{2}$ was registered at Russe. Some of the damages on masonry structures in NE Bulgaria, due this strong event, documented at similar epicentral distancesbut at different azimuths, are shown in fig. 2.
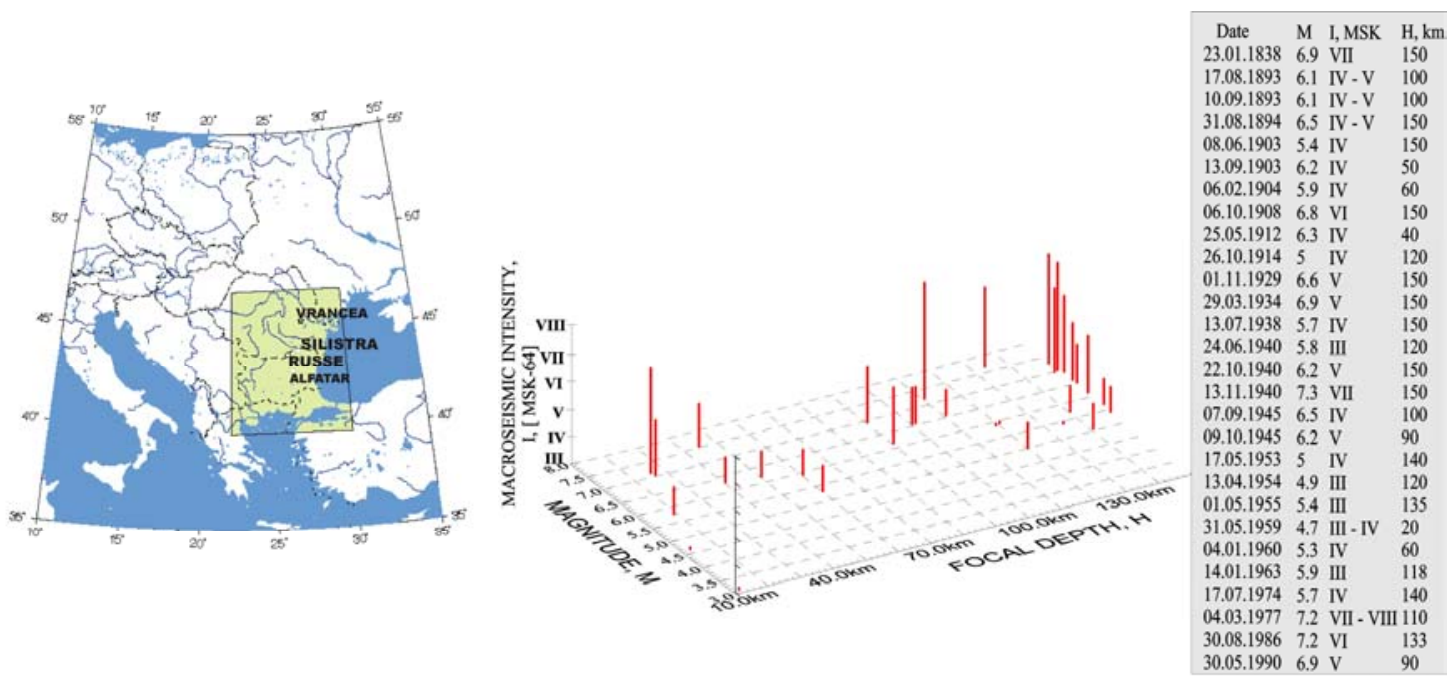

Figure 1. Left: Schematic location of Vrancea Seismic zone and Russe, Silistra and Alfatar towns. Right: Macroseismic intensity reported at Russe due to Vrancea intermediate-depth earthquakes, plotted versus earthquakes' focal depth and magnitude [Paskaleva et al., 2001]
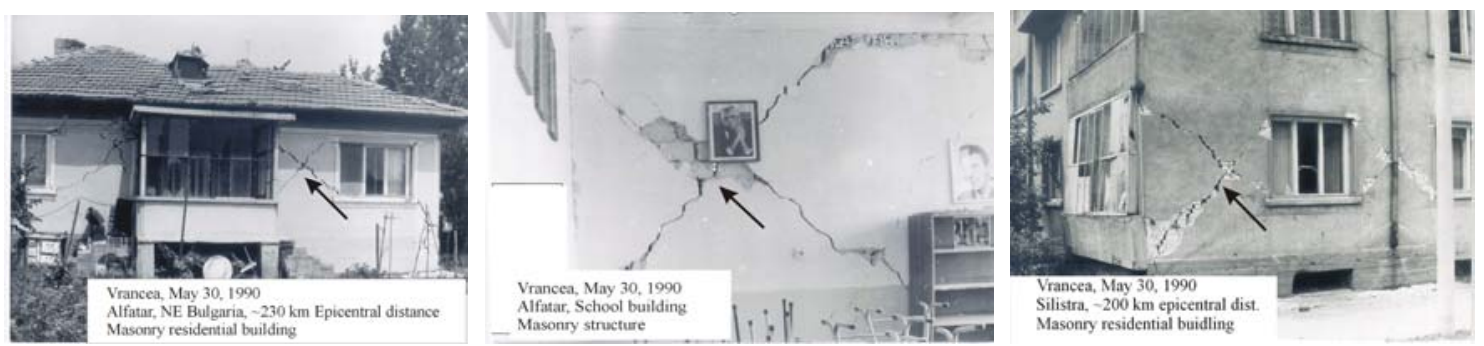

Figure 2. Some damages in NE Bulgaria, due to the Vrancea Earthquake of May 30, 1990. The schematic location of the towns mentioned in fig. 2 is shown in fig. 1 , left. 
Accelerograms due to the Vrancea intermediate-depth earthquakes have been recorded by the seismic networks of Romania, the Academy of Science from Moldova, and the Bulgarian Academy of Sciences. Waveforms (recorded accelerograms) in Romania and Bulgaria, due to the Vrancea earthquakes, are available through the existing strong motion databases [Nenov et al., 1990; Ambraseys et al., 2000; Earthquake Strong Motions, 1990]. A recent detailed analysis of the Bulgarian data applying the moving windows technique, a new data processing technique in the frequency - time domain, and tables with the main characteristics of the recorded accelerograms were provided by Paskaleva [Paskaleva \& Kouteva, 2000]. The control periods, $\mathrm{T}_{\mathfrak{c}}$, of the response spectra extracted from the available Bulgarian records are $\mathrm{T}_{\mathrm{c}}=0.4-1.6 \mathrm{~s}$.

Maps of practical use, as design ground accelerations, maximum velocities and displacements, have been recently produced [Panza et al., 2000 a; Radulian et al., 2000; Panza et al., 2001] applying an advanced deterministic procedure [Costa et al., 1993; Panza et al., 2000 b] for different Vrancea earthquake scenarios. From the deterministic modelling it can be concluded that the Vrancea earthquakes can produce ground displacements in NE Bulgaria up to $30-60 \mathrm{~cm}$, velocities up to 50 $100 \mathrm{~cm} / \mathrm{s}$ and peak accelerations over $50 \%$ of $\{\mathrm{g}\}$. These computed DGA values for NE Bulgaria significantly exceed the prescribed seismic loading in the BG Code'87 and the recorded PGA for VR901.

Some investigations concerning the modelling of long period ground motion and the influence of the seismic source parameters on the ground motion (frequency content up to $1 \mathrm{~Hz}$ ) due to strong intermediate-depth Vrancea earthquakes have been performed in the framework of the UNESCOIUGS-IGCP Project 414, www.ictp.trieste.it, [Paskaleva et al., 2001; Kouteva et al., 2002; Panza et al., 2002].

The main idea of this study is to extend the investigations to higher frequencies, of earthquake engineering interest, considering the new structural data defining the average properties of the profile Vrancea - Russe [Cioflan, 2003] as the bedrock structure. Thus the synthetic seismic load, at selected sites in the town of Russe, NE Bulgaria, due to the Vrancea earthquake of May 30 (VR901, $\mathrm{M}_{\mathrm{w}}=6.9$, focal depth $\mathrm{H}=74 \mathrm{~km}$ ), has been computed applying a deterministic analytical procedure, based on modal summation and modal coupling techniques [Panza et al., 2001]. The synthetic seismic signals have been compared with available instrumentally recorded accelerations, considering separately frequencies of 1 and $2 \mathrm{~Hz}$.

\section{The method and the data}

To simulate the ground motion at Russe a deterministic analytical approach, combining the modal summation technique, applied to model the seismic wave propagation between the seismic source and the site of interest, [Panza 1985; Panza \& Suhadolc, 1987; Florsh et al., 1991] with the mode coupling approach [Vaccari et al., 1989; Romanelli et al. 1996; Romanelli et al., 1997], used to model the seismic wave propagation through the anelastic, laterally inhomogeneous, sedimentary media of the target site, was implemented. Thus theoretical acceleration, velocity and displacement time histories at the recording site at Russe were computed. A model, consisting of two horizontally layered halfspaces in welded contact, fig.3, has been adopted for these numerical experiments. It includes the bedrock structure, representative of the geological profile between the seismic source and the site of interest, and the target site structure. The detailed geological and geotechnical data available for the 
uppermost $100 \mathrm{~m}$ in Russe [Evlogiev, 1993] have been used to define the uppermost part of the local model [Paskaleva et al., 2001]. A regional structural model (bedrock model) representative of the path Vrancea-Russe, which passes through the Carpathians and the Moesian Platform, has been provided in [Radulian et al., 2000]. With the progress of the UNESCO- IUGS - IGCP Project 414 new geological information about the bedrock become available [Cioflan, 2003 \& personal communications] and new computations have been started both in Romania and Bulgaria. The adopted models used in these computations are shown in fig. 3. The seismic source has been modelled as a buried double couple. The data provided in [Dziewonsky et al., 1991], $\mathrm{M}_{\mathrm{w}}=6.9$, focal depth of $74 \mathrm{~km}$, strike $=236^{\circ}$, dip $=63^{\circ}$ and rake $=101^{\circ}$ have been used in the computations.
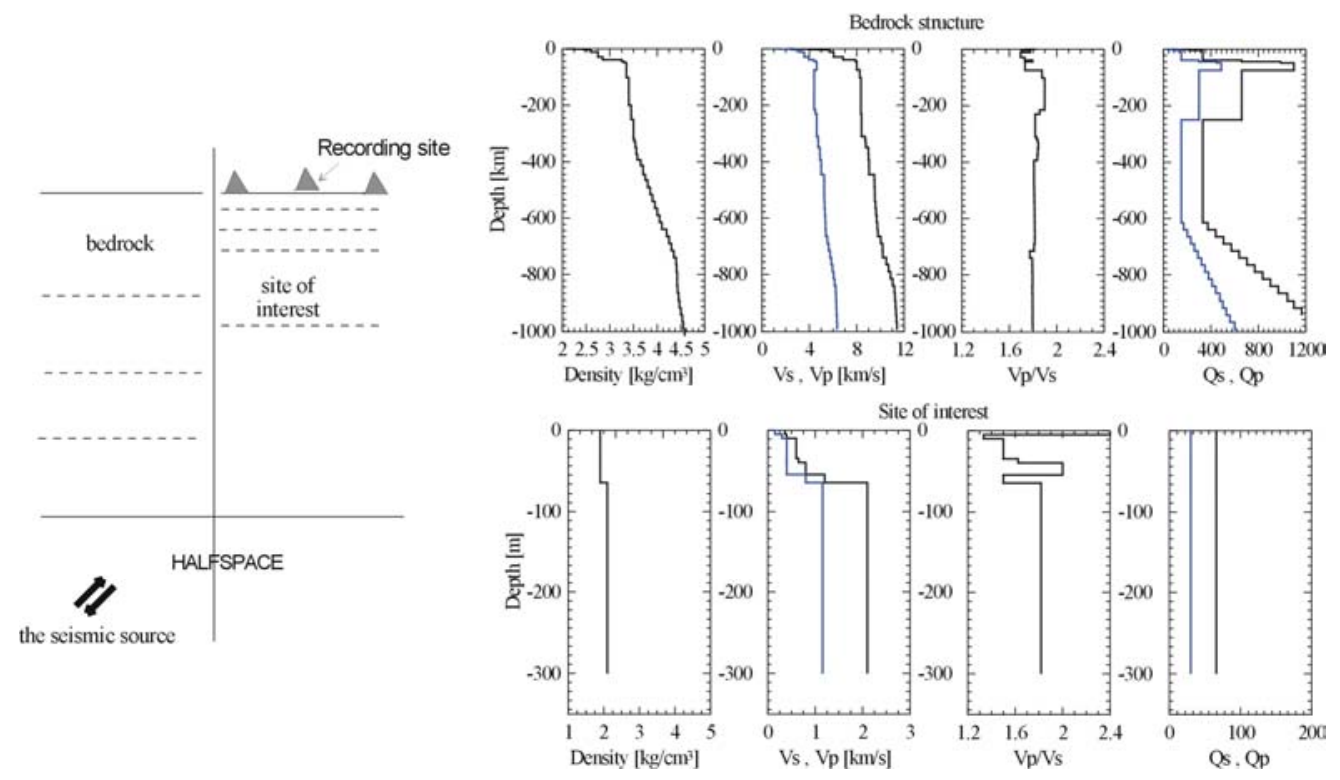

Figure 3. Structural models for the bedrock (top) by Cioflan, pp com., and for the target site (bottom) by [Paskaleva et al., 2001], which have been used for the computation of the synthetic ground motion.

\section{Discussion of the Results}

The available, instrumentally corrected, accelerograms have been rotated and low-passed filtered with cut-off frequencies of $1 \mathrm{~Hz}$ and $2 \mathrm{~Hz}$. Using the available data, synthetic accelerograms, velocigrams and displacements have been computed for the transverse (TRA), radial (RAD) and vertical (VER) ground motion components. Response spectra for 5\% damping and absolute energy input [Uang and Bertero, 1990; Decanini and Mollaioli, 1998] have been computed. Both synthetic and observed data have been processed using the SeismoSignal data processing package, 2.00, and peak ground acceleration, velocity and displacement' values, PGA, PGV and PGD, PGV/PGD ratio, Arias Intensity and A95 (the acceleration level below which $95 \%$ of the total Arias intensity is contained) have been computed. Comparisons between the synthetic and observed signals for frequencies up to $1 \mathrm{~Hz}$ and $2 \mathrm{~Hz}$ are shown in figs. 4 and 5, respectively and Table 1.

Considering the fact that no data fitting has been done and that all the data have been used as they were published in the literature, both comparisons, shown in fig. 4 and 5 respectively, can be accepted as successful and very encouraging. For the case of frequencies up to $1 \mathrm{~Hz}$, fig. 4 and Table 1 , the best fit in terms of peak acceleration (PGA), velocity (PGV), displacement (PGD), PGV/PGD 
ratio, A95 and response spectra, SA 5\%, has been obtained for the TRA component, (e.g. observed $\mathrm{PGA}=14.10$ against computed $\mathrm{PGA}=13.90 \mathrm{~cm} / \mathrm{s}^{2}$ ). The origin of the time scales of synthetic and observed signals differ, since the available records were obtained by SMA - 1 analogue instrument that was not equipped by any time synchronising device. The computed TRA PGA, PGV and PGD and the energetic parameters, Arias intensity, A95, are very close to the observed ones. The synthetic TRA SA5\% amplitudes are also close to the observed one almost over the whole frequency interval considered, while the computed TRA absolute input energy, EI, amplitudes are larger than the observed ones respectively.
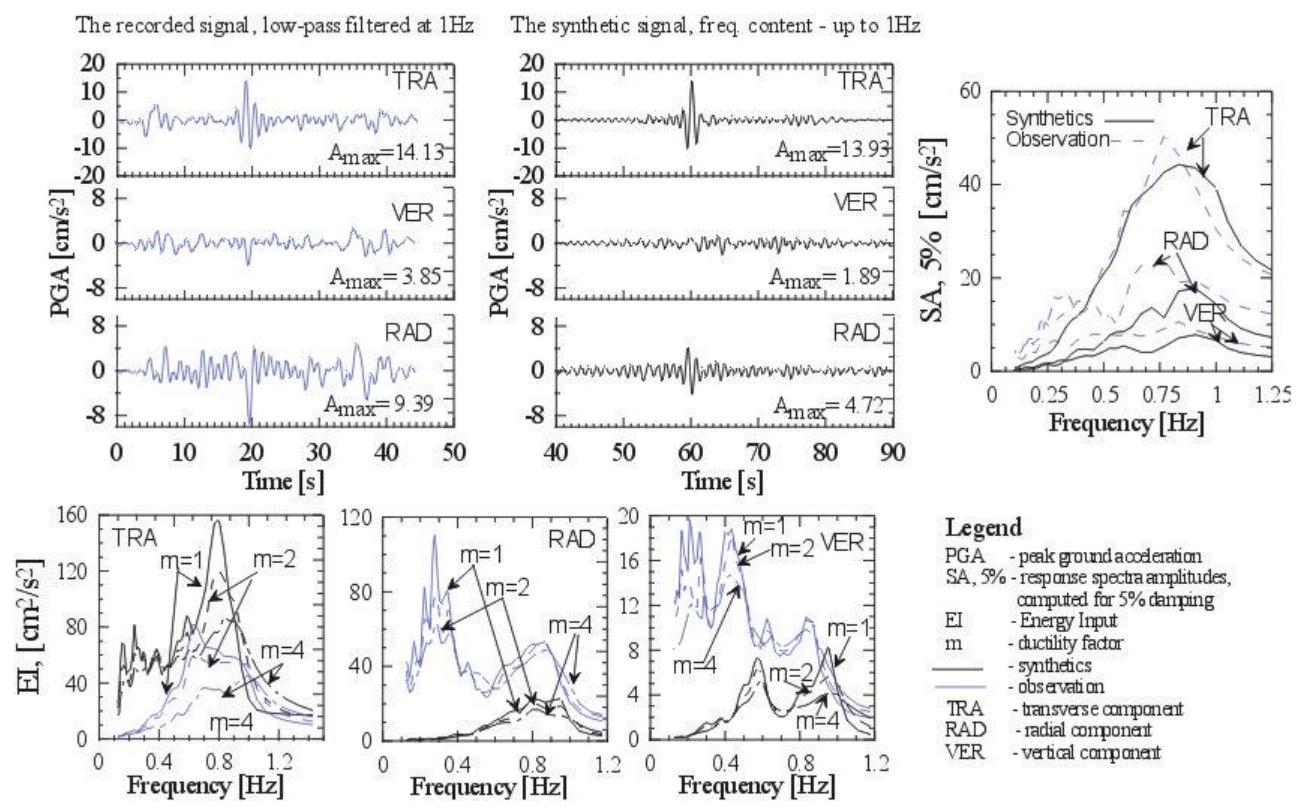

Figure 4. Vrancea earthquake, May 30, 1990, Russe recording station, NE Bulgaria. Comparison between the computed and observed signals, frequency up to $1 \mathrm{~Hz}$ considered. Top-Left: The recorded accelerogram, lowpassed filtered with cut-off frequency of 1Hz. Top - middle: The computed accelerograms. Top-Right:

Comparison between both computed (solid lines) and observed (dashed lines) response spectra, computed for 5\% damping. Bottom: Comparison between synthetic (thick line) and observed (thin line) absolute energy input, computed for different ductility factors $\mathrm{m}=1,2$ and 4. Transverse (TRA), radial (RAD) and vertical (VER) ground motion component are shown. 
Table 1. Comparison between the synthetic and the observed signals in terms of representative ground motion parameters. The shadowed values correspond to the theoretical signals.

\begin{tabular}{|c|c|c|c|c|c|c|}
\hline $\begin{array}{l}\text { Ground motion } \\
\text { component }\end{array}$ & $\begin{array}{c}\text { PGA } \\
{\left[\mathrm{cm} / \mathrm{s}^{2}\right]}\end{array}$ & $\begin{array}{c}\mathrm{PGV} \\
{[\mathrm{cm} / \mathrm{s}]}\end{array}$ & $\begin{array}{l}\text { PGD } \\
{[\mathrm{cm}]}\end{array}$ & $\begin{array}{c}\text { Arias } \\
\text { Intensity } \\
\mathrm{cm} / \mathrm{s}\end{array}$ & A95 $[\mathrm{g}]$ & $\begin{array}{c}\mathrm{PGV} / \mathrm{PGA} \\
{[\mathrm{s}]}\end{array}$ \\
\hline 1 & 2 & 3 & 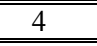 & 6 & 7 & 8 \\
\hline \multicolumn{7}{|c|}{ Frequency up to $1 \mathrm{~Hz}$ considered } \\
\hline \multicolumn{7}{|c|}{ TRA } \\
\hline Vrs2dh1t & 13.90 & 3.01 & 0.94 & 0.228 & 0.0137 & 0.216 \\
\hline Rsf010t & 14.10 & 2.95 & 0.80 & 0.414 & 0.0140 & 0.209 \\
\hline \multicolumn{7}{|l|}{ RAD } \\
\hline Vrs2dh1r & 4.38 & 1.02 & 0.25 & 0.064 & 0.0042 & 0.233 \\
\hline Rsf010r & 9.40 & 2.50 & 0.96 & 0.246 & 0.0092 & 0.266 \\
\hline \multicolumn{7}{|l|}{ VER } \\
\hline Vrs2dh1v & 1.90 & 0.45 & 0.19 & 0.021 & 0.0018 & 0.237 \\
\hline Rsf010v & 3.90 & 0.95 & 0.48 & 0.060 & 0.0038 & 0.244 \\
\hline \multicolumn{7}{|c|}{ Frequency up to $2 \mathrm{~Hz}$ considered } \\
\hline \multicolumn{7}{|c|}{ TRA } \\
\hline Vrs2dh2t & 52.80 & 12.40 & 3.85 & 3.763 & 0.0517 & 0.235 \\
\hline Rsf020t & 29.40 & 4.66 & 1.04 & 1.714 & 0.0289 & 0.159 \\
\hline \multicolumn{7}{|l|}{ RAD } \\
\hline Vrs2dh2r & 16.70 & 2.38 & 0.45 & 0.494 & 0.0162 & 0.142 \\
\hline Rsf020r & 18.20 & 2.40 & 0.93 & 0.657 & 0.0179 & 0.132 \\
\hline \multicolumn{7}{|l|}{ VER } \\
\hline Vrs2dh2v & 6.30 & 0.94 & 0.19 & 0.080 & 0.0061 & 0.149 \\
\hline Rsf020v & 7.80 & 0.95 & 0.48 & 0.150 & 0.0038 & 0.121 \\
\hline
\end{tabular}

For both RAD and VER components all the synthetic values underestimate significantly the observed one. The best fit for these components is obtained for the PGV/PGA ratio (RAD: 0.233 computed against 0.266 observed; VER: 0.237 against 0.244 respectively), Table 1 . Both RAD and VER EI computed from the synthetic signals underestimate the EI obtained from the recorded acceleration. The best qualitative EI fit has been observed for the RAD component, in the frequency interval $0.6-1$ $\mathrm{Hz}$.

The second comparison, fig. 5 and Table 1, shows that the synthetic TRA component significantly overestimates the observed one for all investigated ground motion parameters. The best fit in terms of PGA, PGV, Arias intensity, A95 and PGV/PGA has been observed for the RAD component (e.g. PGA = 16.7 computed against $18.2 \mathrm{~cm} / \mathrm{s}^{2}$ observed). All the investigated RAD ground motion parameters, derived from the synthetic signal, except the PGA/PGV ratio, are lower than the corresponding values, obtained from the recorded signal. The computed RAD SA 5\% are larger than the observed one for frequencies between 1 and $2 \mathrm{~Hz}$. Very good EI fit of synthetics and observation is observed for the RAD component over the frequency interval $1.25-2.25 \mathrm{~Hz}$. The VER component shows lower synthetic values for all studied parameters, except the Arias intensity and A95. The best VER fit has been observed for PGA and PGV (Table 1).

\section{Conclusions}

The Vrancea seismic record and the recently constructed deterministic maps show that the seismic hazard in NE Bulgaria is mainly controlled by the large Vrancea intermediate-depth earthquakes. 
Different structures, located at epicentral distances of about $250 \mathrm{~km}$ far from these sources may be prone to severe earthquake hazard. An advanced deterministic ground motion modelling technique has been proved to be capable to provide theoretical seismic loading, applicable for engineering purposes, exploiting the large quantities of already available data about sources and media crossed by waves. The method discussed addresses the issue of the deterministic definition of ground motion in a way, which permits a generalization to locations in which there is little or none seismic history. This philosophy is a result of the progress in the fields of geophysics, seismology and earthquake engineering and has been recently independently encouraged both by seismologists and engineers.
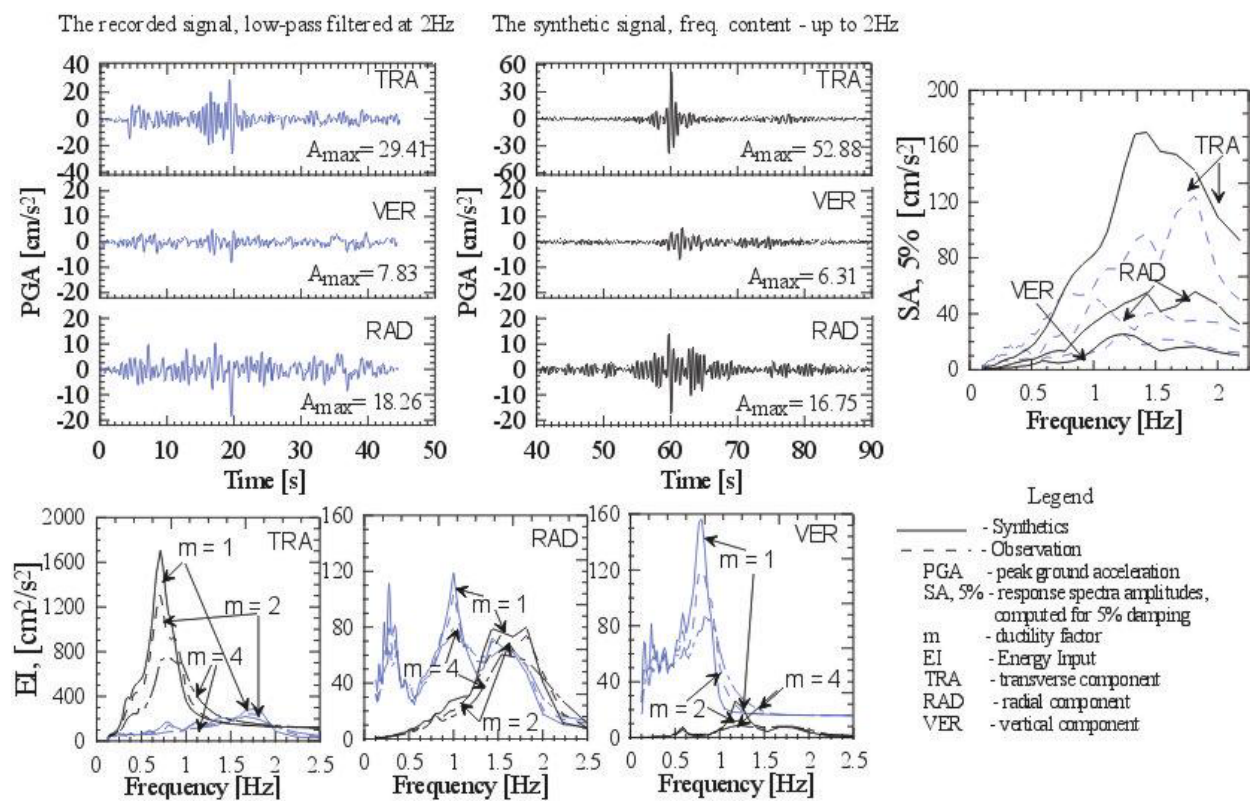

Figure 5. Vrancea earthquake, May 30, 1990, Russe recording station, NE Bulgaria. Comparison between the computed and the observed signals. Frequency up to $1 \mathrm{~Hz}$ are considered. Top-Left: The recorded accelerogram, low-passed filtered with cut-off frequency of 1Hz. Top - middle: The computed accelerograms. Top-Right: Comparison between both computed (solid lines) and observed (dashed lines) response spectra, computed for 5\% damping. Bottom: Comparison between both synthetic and synthetic absolute energy input, computed for different ductility factors $m=1,2$ and 4 . Transverse (TRA), radial (RAD) and vertical (VER) ground motion component are shown.

\section{Acknowledgements}

Carmen Cioflan from NIEP-Romania and Dr. F. Vaccari from DST-University of Trieste are warmly acknowledged for the fruitful discussions. CEI, ICTP and DST - University of Trieste are acknowledged for the provided facilities, which have been used to complete this study. This study is also a contribution to projects MON NZ1202 and MON NZ 100, supported by the Bulgarian National Science Foundation.

\section{References}

Ambraseys N., Smit P., Berardi R., Rinaldis D., Cotton F., Berge C. (2000) Dissemination of European Strong-Motion Database, Data CD-ROM collection, European Council, Environment and Climate Research Programme.

Balan St, Cristescu V, Cornea I. (Editors) (1982) "Consequences due to the earthquake of March 4, 1977 in Romania", Editura Academiei, Bucuresti, Romania (in Romanian) 
Brankov G., Bonchev E., Ignatiev N., Boncheva H., Hristoskov L., Paskaleva I. (Editors) (1983) "Vrancea Earthquake in 1977. Its after-effects in the People's Republic of Bulgaria. Sofia”, Publishing house of the Bulg. Ac. of Sci., Sofia, Bulgaria (In Bulgarian).

Cioflan, C.O. (2003) DST Visiting report, DST, University of Trieste.

Costa G., Panza G. F., Suhadolc P., Vaccari F. (1993) Zoning of the Italian territory in terms of expected PGA derived from complete synthetic seismograms. In: "Proc. Of School Geoph. Explor. Areas Complex Geology", Erice 1992. Jrn. Appl. Geophys 1993 (30): 143-160.

Decanini L. and Mollaioli, F. (1998) Formulation of Elastic Input Energy Spectra, Earthquake Engineering and Structural Dynamics, 27, 1503 - 1522. Engineering and Structural Dynamics, 27, 1503 - 1522.

Dziewonsky A. M., Ekstrom G., Woodhouse J. H., Zwart G. (1991) Centroid Moment Tensor Solutions for April-June 1990, Physics of the Earth and Planetary Interiors, (66): 133-143.

Evlogiev J. (1993) "Paleogeography and stratigraphy of the Early Pleistocene in Peridanube Northeast Bulgaria", Ph. D. thesis Geological Institute, Bulgarian Academy of Sciences, Sofia.

Earthquake Strong Motion (1990), 3-Volume Data CD-ROM Collection, National Geophysical Data Center, pkd@ngdc.noaa.gov, info@ngdc.noaa.gov.

Florsch N., Faeh D., Suhadolc P., Panza G. F. (1991) Complete synthetic seismograms for high-frequency multimode SH-waves, PAGEOPH (136): 529-560.

Medvedev S. V. (1977) Seismic Intensity Scale MSK-76. Publ. Inst. Geoph. Pol. Acad. Sc. 1977 (117): $95-$ 102.

Kouteva M., Panza G.F., Paskaleva I., Romanelli F. (2002) A parametric analysis of the seismic input in NE Bulgaria (russe site) due to RECENT Vrancea Intermediate - Depth Earthquakes, $27^{\text {th }}$ EGS Assembly, Nice, May 2002.

Nenov D., Georgiev G., Paskaleva I., Lee V. W., Trifunac M. (1990) Strong Ground motion data in EQINFOS: accelerograms recorded in Bulgaria between 1981-1987, Bulg. Acad. of Sci., Centr. Lab. for Seism. Mech. And Eq. Eng., \& Dept. of Civ. Eng. Dpt. No 90-02, Univ. of S. California, L. A., California.

Panza G F. 1985 "Synthetic seismograms: the Rayleigh waves modal summation" J. Geophysics, (58): 125145.

Panza G. F., Suhadolc P. (1987) Complete strong motion synthetics. In: "Seismic Strong Motion Synthetics". Bolt B. A, Editor. Orlando: Academic Press, Computational Techniques (4): 153-204.

Panza G. F., Radulian M., Trifu C. I., Editors, (2000) a, Seismic Hazard of the Circum-Pannonian Region, PAGEOPH Topical Volumes, Birkhauser, Vol 157, No. 1/2.

Panza G. F., Vaccari F., Cazzaro R. (2000) b, Deterministic seismic hazard assessment. In: Wenzel F, Lungu D, Novak O, Editors. "Vrancea Earthquakes: Tectonics, Hazard and Risk Mitigation", Netherlands: Kluwer Academic Publishers: 269-286.

Panza G. F., Vaccari F. (2000) Introduction. In: Seismic Hazard of the Circum Pannonian Region In: Seismic Hazard of the Circum Pannonian Region. Panza G. F, Radulian M, Trifu C. I, Editors. Pageoph Topical Volumes, Basel: Birkhauser Verlag, 2000: 5-10.

Panza, G.F., Romanelli, F., Vaccari, F. (2001) Seismic wave propagation in laterally heterogeneous anelastic media: theory and applications to seismic zonation, Advances in geophysics 43, 1-95.

Panza G. F., Cioflan C.O., Kouteva M., Paskaleva I., Romanelli F., Marmureanu G. (2002) An innovative view to the seismic hazard from strong Vrancea Intermediate-Depth Earthquakes: the Case Studies of BUcharest (Romania) and RUSSE (Bulgaria), Proc. of 12ECEE (On CD, Ref. 230), September, 2002, London, UK.

Paskaleva I., Kouteva M. (2000) An Approach for Microzonation of the Town of Russe in Connection of Recent Vrancea Earthquakes and Shabla Zone. Report on Bilateral project on Seismic Hazard and Risk Assessment of Selected Cities in the Balkan Region. Trieste: DST, University of Trieste, 2000.

Paskaleva I., Kouteva M., Panza G. F., Evlogiev J., Koleva N., Ranguelov B. (2001) Deterministic approach of seismic hazard assessment in BG, Case study NE Bulgaria - the town of Russe, In Proc. of the Workshop on Deterministic Approach of Seismic Zonation of Some Balkan Countries, Tirana, Albania, 2001: 51-73. 
Radulian M., Vaccari F., Mandrescu M., Panza G. .F, Moldoveanu C. (2000) Seismic Hazard of Romania. In: Seismic Hazard of the Circum Pannonian Region. Panza G. F, Radulian M, Trifu C. I, Editors. Pageoph Topical Volumes, Basel: Birkhauser Verlag: 221-248.

Romanelli F., Bing Z., Vaccari F., Panza G. F. (1996) Analytical computation of reflection and transmission coupling coefficients for Love waves, Geophys. J. Int. (125): 132-138.

Romanelli F., Bekkevold J., Panza G. F. (1997) Analytical computation of coupling coefficients in nonpoissonian media, Geoph. J. Int. (129): 205-208.

Uang, C. M. and Bertero, V. V. (1990) Evaluation of seismic energy in structures. Earthquake Engineering and Structural Dynamics, 19, 77-90.

Vaccari, F., Gregersen S., Furlan M. and Panza G. F. (1989) Synthetic seismograms in laterally heterogeneous, anelastic media by modal summation of P-SV waves. Geophys. J. Int., 99, 285-295. 